\title{
The Synthesis of Cuprous Oxide Nanowires in the Presence of Oxygen using a Hot Tube Thermal Evaporation Method
}

\author{
Muhammad Arif Khan ${ }^{1 *}$, Samsudi Sakrani ${ }^{2}$, Yussof Wahab ${ }^{3}$, Syahida Suhaimi ${ }^{1}$ and Rosnita Muhammad ${ }^{4}$ \\ ${ }^{1}$ Department of Physics, Faculty of Science, UTM, 81310 UTM Skudai, Johor, Malaysia; \\ ${ }^{2}$ Ibnu Sina Institute, UTM, 81310 UTM Skudai, Johor, Malaysia \\ ${ }^{3}$ UTM Razak School of Engineering and Advanced Technology UTM Kuala Lumpur Level 7, Razak Tower Jalan Semarak 54100 Kuala Lumpur Malaysia \\ ${ }^{4}$ Sustaiability Research Alliance, UTM, 81310 UTM Skudai, Johor, Malaysia \\ *Corresponding Author: marifkhan_qau@hotmail.com
}

\section{Article history :}

Received 23 November 2015

Accepted 15 December 2015

\section{GRAPHICAL ABSTRACT}

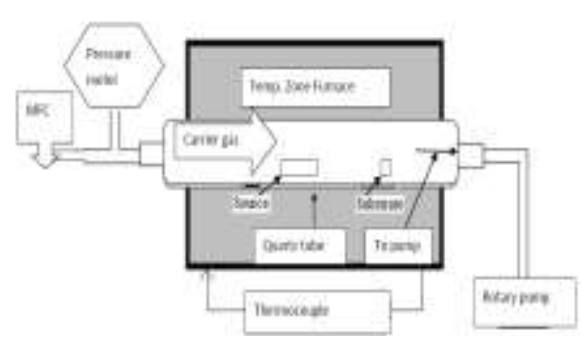

\begin{abstract}
Cuprous oxide nanowires have been synthesized by heating copper foil in the presence of oxygen rich environment using a hot tube vacuum thermal evaporation method. The effect of growth parameters such as growth time, temperature and oxidative environment on the morphology of the nanowires is investigated. The growth of cuprous oxide nanowires from copper foils thermally oxidized in the presence of oxygen rich at temperatures between 300 and $5000 \mathrm{C}$. The nanowires were formed within the temperature range of $400-5000 \mathrm{C}$ with diameters and length between $25-100 \mathrm{~nm}$ and length $1-4 \mu \mathrm{m}$, respectively. This gave an estimate of aspect ratio around 40. Observation from FESEM results revealed the optimal growth of cuprous oxide nanowires which occurred at oxidation times for $1 \mathrm{~h}, 1 / 2 \mathrm{~h}$ and 25 minutes and flow rates of oxygen at $0.09 \mathrm{psi}, 0.12 \mathrm{psi}$ and $0.08 \mathrm{psi}$. The atom $\%$ of copper and oxygen were measured using EDX and their existence were later confirmed by XRD, essentially indicated by $40 \%$ an $60 \%$ of copper and oxygen contents, respectively.
\end{abstract}

Keywords: Hot tube vacuum thermal evaporation, Cuprous oxide nanowires, Copper foils, Thermal Oxidation, Growth time

(c) 2015 Penerbit UTM Press. All rights reserved http://dx.doi.org/10.11113/mjfas.v11n4.398

\section{INTRODUCTION}

Cuprous oxide $\left(\mathrm{Cu}_{2} \mathrm{O}\right)$ is a p-type semiconductor with cubic crystalline structure $\left(\mathrm{a}=4.27^{\circ} \mathrm{A}\right)$ and energy gap $2.1 \mathrm{eV}$ [1]. Cuprous oxide, $\mathrm{Cu}_{2} \mathrm{O}$ is an attractive material for the absorber layers of photovoltaic devices, because it has direct band gap energy of $2.1 \mathrm{eV}$ and a high absorption coefficient, which enable the fabrication of thin film solar cells [2-4]. In addition, $\mathrm{Cu}_{2} \mathrm{O}$ layers have several advantages such as nontoxicity and low cost, compared with other types of thin film solar cells including CIGS solar cells $[5,6]$.

In recent years, there has been increasing interest in developing one-dimensional (1D) $\mathrm{Cu}_{2} \mathrm{O}$ nanostructures such as nanowires, nanorods and nanotubes due to their unique properties and potential applications in electronics, optics, photonics and sensing devices [7-9]. Nanowires and nanorods of various semiconductor materials include $\mathrm{Si}$, $\mathrm{Ge}, \mathrm{GaN}, \mathrm{ZnO}$, and so forth, have been the focus of intense studies in the past years [10]. During the last few years 1D nanowires / nanorods of $\mathrm{Cu}_{2} \mathrm{O} / \mathrm{CuO}$ synthesized by various growth techniques such as thermal decomposition of
$\mathrm{CuC}_{2} \mathrm{O}_{4} \quad$ precursors [11], hydrothermal decomposition route [12], self catalytic growth process [13], and so forth. In synthesizing 1D nanowires / nanorods the important factors are control of composition, size and crystallinity. Moreover, studying the fundamental properties of nanowires as well as their applications, the methods of pre parathion of the 1D nanostructures should be simple for producing bulk quantities and amenable to control diameter and length. In comparison to various synthesizing methods, thermal annealing or thermal oxidation of copper foil is a simple, convenient, and the fast method for synthesis nanostructures.

Many studies on synthesizing $\mathrm{CuO} / \mathrm{Cu}_{2} \mathrm{O}$ nanowires by thermal oxidation of copper foils in oxygen atmosphere have been reported up to now [14-28]. However less report has been given on $\mathrm{Cu}_{2} \mathrm{O}$ nanowires by heating copper foil in the presence of oxygen using a hot tube vacuum thermal evaporation compared to widely use chemical methods. This research is aimed at improving the properties of $\mathrm{Cu}_{2} \mathrm{O}$ NWs and has focused on the influence of growth time, temperature and oxidative environment on the morphology of the nanowires. 


\section{EXPERIMENTS}

$\mathrm{Cu}_{2} \mathrm{O}$ nanowires were synthesized on $\mathrm{Cu}$ foils in the presence of oxygen rich environment using a hot tube vacuum thermal evaporation method at the temperatures of 400 and $500{ }^{\circ} \mathrm{C}$ for different time $(1 \mathrm{~h}, 1 / 2 \mathrm{~h}$ and 25 minutes). The experiment was carried out on the copper foils with purity of $99.96 \%$ and $0.2 \mathrm{~mm}$ in thickness. First we have used four copper foils (purchased from Nilaco Co. Ltd.) were used as substrates. Foils were cut into standard sizes of $1 \mathrm{~cm} \times 1 \mathrm{~cm}$. The substrates were washed by dilute hydrochloric acid to remove the native oxide layer and contamination and then $\mathrm{Cu}$ foils were washed in distilled water and absolute alcohol under an ultrasonic bath for 10 min respectively. After dried in air or by $\mathrm{N}_{2}$ flow the cleaned samples were placed in an alumina boat. The alumina boat was positioned in the center of a quartz tube, and the quartz tube was mounted in the middle of a horizontal tube furnace.

Oxidation was initiated by evacuating the tube furnace to a pressure less than $5 \times 10^{-3}$ torr followed by heating the furnace to a temperature of $400-500{ }^{\circ} \mathrm{C}$ under the vacuum. The system was well controlled by adjusting the parameters of temperature, oxygen gas flow rate, growth reaction time. The temperature at which our oxidation takes place, a leak valve introducing ultra high purity oxygen in the tube was opened where the oxidation of the copper foils commenced at a pressure of $5 \times 10^{-2}$ torr for 1-2 hours, following oxidation, the vacuum furnace was quarreled through a stepwise process down to room temperature under successively decreasing oxygen for stable $\mathrm{Cu}_{2} \mathrm{O}$ NWs.

Synthesize in quartz tube furnace which is open on both sides, one of the open side is connected to the pump while the other one is used as inlet for carrier gas which connected to the gas supply. Quartz tube is placed inside a furnace source and substrate materials set inside quartz tube. A schematic for our process is shown in Figure 1.

The substrate was pulled out of the furnace for further analysis. The morphology of the samples was investigated by field emission scanning electron microscope (FE-SEM, Hitachi S-4800) operated at an accelerated voltage of $5 \mathrm{kV}$ combined with EDX for morphological and compositional analysis. The structures of the samples were characterized by X-ray diffraction using $\mathrm{Cu} \mathrm{K}$ radiation $\left(\lambda=1.54 \mathrm{~A}^{\circ}\right)$ with $\theta-2 \theta$ mode ranging from 20 to $60^{\circ}$.

\section{RESULTS AND DISCUSSION}

\section{1 $\mathrm{Cu}_{2} \mathrm{O}$ nanowires and its Structural Properties}

$\mathrm{Cu}_{2} \mathrm{O}$ nanowires were prepared on the copper foil by thermal oxidation in an oxygen rich environment using thermal evaporation system of vacuum quartz

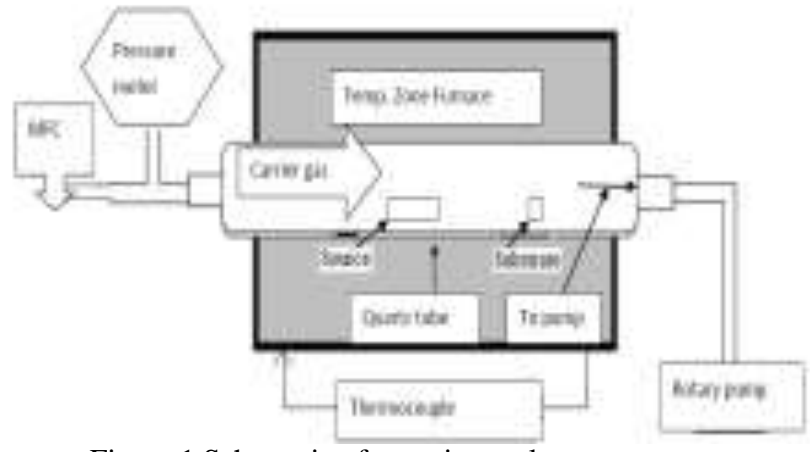

Figure.1 Schematic of experimental setup

tube furnace. The effect of growth parameters such as growth time, temperature and oxidative environment (flow rate of oxygen gas) on the morphology of the nanowires is investigated. It is found that the annealing temperature and the growth time play an important role in the morphology of $\mathrm{Cu}_{2} \mathrm{O}$ nanowires such as the density, the length and the diameter. The length and the density of nanowires increase with prolonging growth time, but if the time is too long, $\mathrm{Cu}_{2} \mathrm{O}$ crystallite grains form instead of nanowires. Annealing copper foils at lower or higher temperature, the density of nanowires is lower. For comparison, the $\mathrm{Cu}$ films upto $150 \mathrm{~nm}$ on glass substrate deposited by Edward vacuum thermal evaporation unit and are oxidized in oxygen rich environment, but we do not find large-scale of nanowires. The possible mechanism is also discussed for the growth of $\mathrm{Cu}_{2} \mathrm{O}$ nanowires.

Using a vacuum furnace is far more advantageous than a traditional tube furnace, because one is able to control both pressure and temperature of the sample and flow rate of oxygen by flow rate meter for synthesis of Copper (I) nanowires, otherwise it's very difficult to obtain NWs from other furnaces by thermal oxidation.

\subsection{Growth parameters of $\mathrm{Cu}_{2} \mathrm{O}$ Nanowires}

Different growth parameters setting will give different structural properties. The variation of growth parameters could help to find the optimum growth condition for of $\mathrm{Cu}_{2} \mathrm{O}$ Nanowires grown on $\mathrm{Cu}$ foil substrate by thermal oxidation. $\mathrm{Cu}_{2} \mathrm{O}$ Nanowires were studied by using different type of microscopy and the best images were chosen. High quality $\mathrm{Cu}_{2} \mathrm{O}$ Nanowires nanowires could be produced if a proper sample preparation is employed.

Nanowires with high aspect ratio could be obtained when the growth process is done steadily with optimum growth condition. EDX studies reveals that with increasing flow rate supplied to the sample, more precursor or source material by which in this case is the flow of oxygen gas will reach and oxidize on the $\mathrm{Cu}$ foil substrate. Growth parameters, which were chosen for $\mathrm{Cu}_{2} \mathrm{O}$ Nanowires grown on $\mathrm{Cu}$ foil substrate by thermal oxidation process are given in the Table 1. 
Table 1 Growth parameters of $\mathrm{Cu}_{2} \mathrm{O}$ Nanowires

\begin{tabular}{|c|c|c|c|c|c|}
\hline Substrate & Thickness & $\begin{array}{c}\text { Oxidation } \\
\text { Temperature }\end{array}$ & $\begin{array}{c}\text { Oxidatio } \\
\mathrm{n} \text { time }\end{array}$ & $\begin{array}{c}\text { Flow rate } \\
\text { of } \\
\text { Oxygen }\end{array}$ & $\begin{array}{c}\text { Weight\% } \\
\text { of Cu:O } \\
\text { (EDX) }\end{array}$ \\
\hline $\begin{array}{c}\text { Cu foil } \\
\text { (S1) }\end{array}$ & $0.05 \mathrm{~mm}$ & 400 & 1 hour & $0.09 \mathrm{psi}$ & $30.46: 5.54$ \\
\hline $\begin{array}{c}\text { Cu foil } \\
\text { (S4) }\end{array}$ & $0.05 \mathrm{~mm}$ & 400 & $1 / 2$ hour & $0.12 \mathrm{psi}$ & $26.59: 8.82$ \\
\hline $\begin{array}{c}\text { Cu foil } \\
\text { (S5) }\end{array}$ & $0.05 \mathrm{~mm}$ & 500 & $25 \mathrm{~min}$. & $0.08 \mathrm{psi}$ & $9.14: 6.41$ \\
\hline
\end{tabular}

\subsection{Morphology of $\mathrm{Cu}_{2} \mathrm{O}$ Nanowires}

$\mathrm{Cu}_{2} \mathrm{O}$ nanowires were grown on the $\mathrm{Cu}$ substrates by thermal oxidation in an oxygen rich environment using thermal evaporation system of vacuum quartz tube furnace .At first; the samples were oxidized at $400{ }^{\circ} \mathrm{C}$ for time $1 \mathrm{~h}$ and $1 / 2 \mathrm{~h}$ and then at $500{ }^{\circ} \mathrm{C}$ for 25 minutes for studying the effect of the time and temperature on the morphology as shown in Fig. ( $2 \& 3)$ and Fig. 4. It can be seen from Fig. $(2 \& 3)$ and Fig. 4 the morphologies of oxide scales formed at $400{ }^{\circ} \mathrm{C}$, showing high density of uniformly curved nanowires, with diameter in the range of $25-100 \mathrm{~nm}$ and length of 1-3 um. In the Fig. ( $2 \& 3)$ that the nanowires with short length of 2.10 micro meter and the diameter is found in the range of $84.2 \mathrm{~nm}$ is shown. The nanowires formed at $400{ }^{\circ} \mathrm{C}$ for $1 / 2 \mathrm{~h}$ and also at $500{ }^{\circ} \mathrm{C}$ for 25 mintus are shown in Fig. 4 and Fig. 5 respectively.

In summary $\mathrm{Cu}_{2} \mathrm{O}$ nanowires on $\mathrm{Cu}$ foils were prepared by thermal oxidation. The annealing temperature and the growth time have an evident influence on the morphology of nanowires. The density and the length of the nanowires increase with the growth time prolonging at $400{ }^{\circ} \mathrm{C}$. When the temperature is elevated to $500{ }^{\circ} \mathrm{C}$ and the growth time is 25 minutes, the density becomes low, and the growth region of nanowires is distinct. Owing to larger internal stress, the diameter of nanowires altered drastically. $\mathrm{CuO}$ crystallites formed instead of nanowires when growth time is too long. But at lower temperature of $300{ }^{\circ} \mathrm{C}$, porous $\mathrm{Cu}_{2} \mathrm{O}$ formed. Large-scale of nanowires was synthesized at $400{ }^{\circ} \mathrm{C}$ for $1 \mathrm{~h}$. For oxidation of $\mathrm{Cu}$ film, no large-scale of nanowires were found because the stress released through the grain boundaries and column structure. Through the diffusion of the atoms supplied by $\mathrm{Cu}$ substrate, the growth of nanowires is driven by internal stress generated in copper substrate and oxide layer during oxidation of $\mathrm{Cu}$ foils.

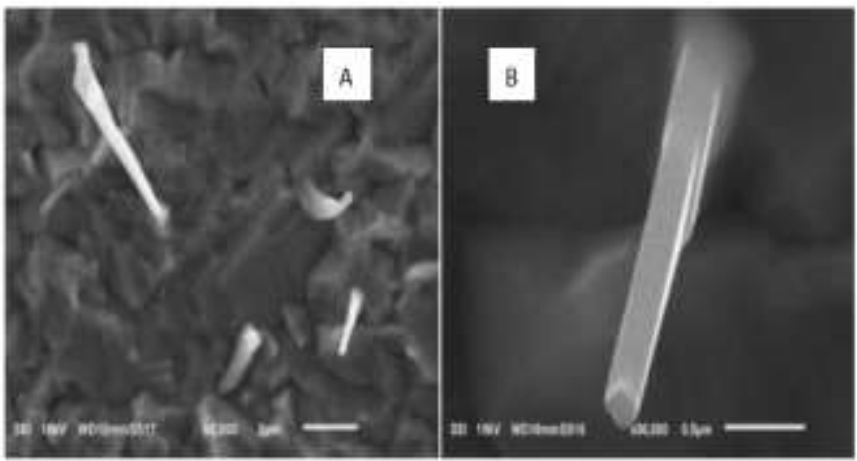

Figure.2 FESEM images of $\mathrm{Cu}_{2} \mathrm{O}$ nanowires (S1).

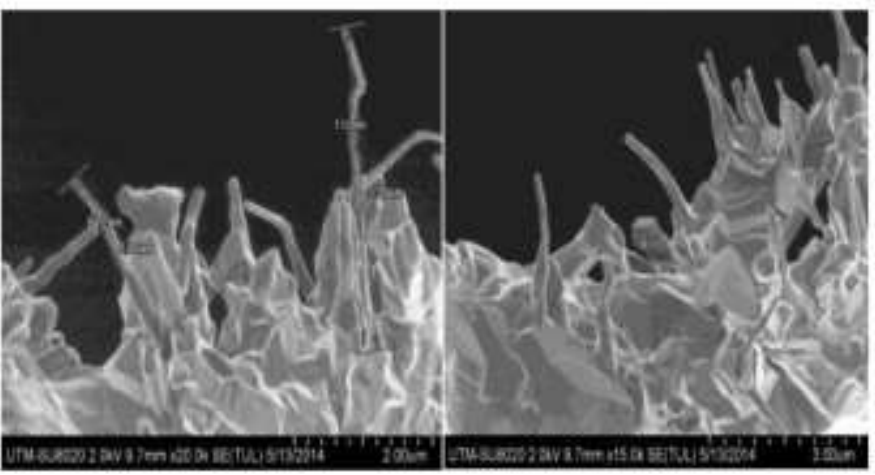

Figure. 3 FESEM of tilt images images of $\mathrm{Cu}_{2} \mathrm{O}$ nanowires (S1).

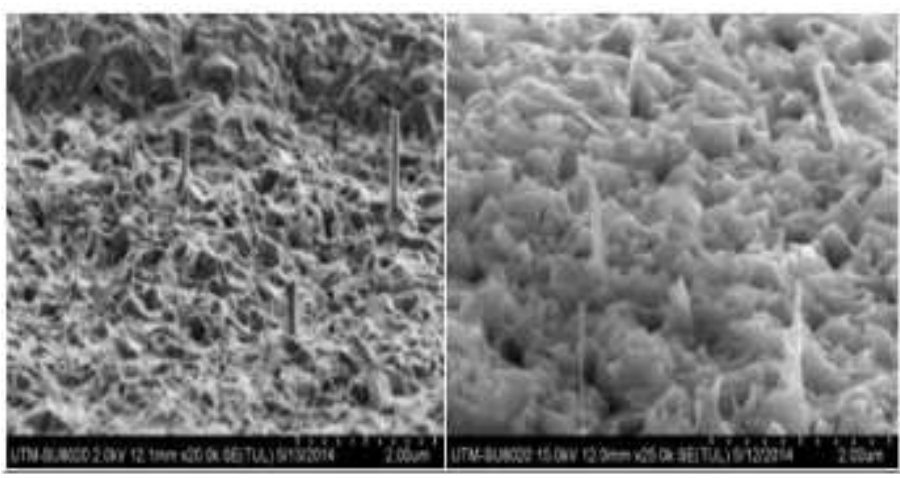

Figure.4 FESEM of tilt images images of $\mathrm{Cu}_{2} \mathrm{O}$ nanowires (S4) 


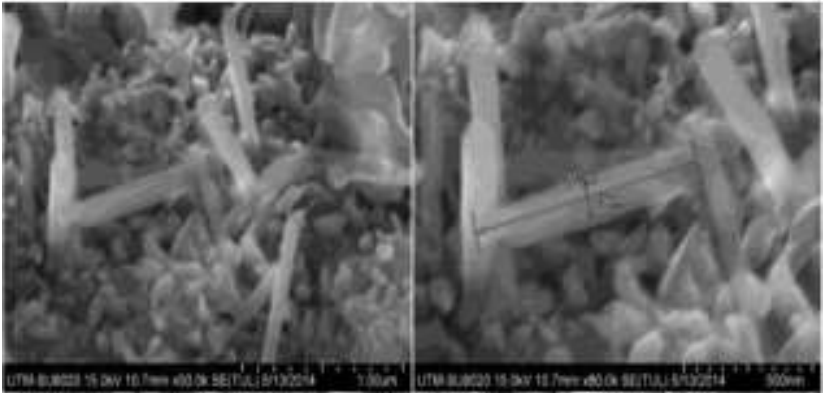

Figure.5 FESEM of tilt images images of $\mathrm{Cu}_{2} \mathrm{O}$ nanowires (S5).

\subsection{Influence of Flow Rate of Oxygen and EDX Analysis}

The influence of Oxygen flow rate is considered to be very significant in determining the nature of $\mathrm{Cu}_{2} \mathrm{O}$ nanowires by oxidation method [27]. Essentially three different concentrations; $0.08,0.09$ and 0.12 psi were fixed, and the corresponding samples were analyzed for each category. Table 2 list down the changes in atom\% of the species involved. Other parameters already shown in Table 1.

Table 2 Effect of oxygen gas flow rate

\begin{tabular}{|l|l|l|l|l|}
\hline Substrate & $\begin{array}{c}\text { Oxygen Flow Rate } \\
\text { (Psi) }\end{array}$ & $\begin{array}{c}\mathrm{Cu} \\
\text { (Atong\%) }\end{array}$ & $\begin{array}{c}0 \\
\text { (Atom\%) }\end{array}$ & Aspect Ratio \\
\hline Cu Foll(S1) & 0.09 psi & 58.04 & 41.96 & 7.06 \\
\hline Cu Fod (S4) & 0.12 psi & 43.14 & 56.86 & 1336 \\
\hline Cu Foll(S5) & 0.08 psi & 26.41 & 73.59 & 4.87 \\
\hline
\end{tabular}

The above results indicate a significant influence of oxygen flow rate on the both atom\% and aspect ratio. For samples $\mathrm{S} 1$ and $\mathrm{S} 4$ at temperature $400{ }^{\circ} \mathrm{C}$, the flow rate of oxygen for sample $\mathrm{S} 4$ increased, thus allowing more oxidation at the copper substrate to produce $\mathrm{Cu}_{2} \mathrm{O}$ nanowires with improved densities and aspect ratios. Except for sample S5 for 0.08 psi at temperature $500{ }^{\circ} \mathrm{C}$ the discrepancy might be caused by the limited number of samples analyzed at this stage. This result suggests a flow rate of $0.12 \mathrm{psi}$ at a temperature $400{ }^{\circ} \mathrm{C}$ and oxidation time $1 / 2 \mathrm{~h}$ for producing better aspect ratio of $\mathrm{Cu}_{2} \mathrm{O}$ nanowires. FE-SEM and EDX result for a single nanowire is shown in Fig. 6 for sample (S4).

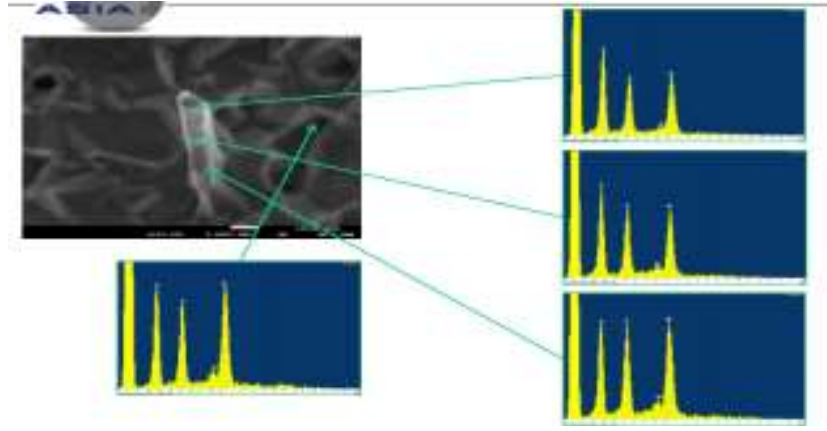

Figure.6 FE-SEM and EDX result (S4)

\subsection{XRD Analysis}

The crystal structure and phase composition were identified by X-ray diffraction (XRD, Diffraktometer Siemens) using a $40 \mathrm{kV}, 30 \mathrm{~mA}, \mathrm{Cu}-\mathrm{K} \alpha \mathrm{X}$-ray. A scanning step of degree of $0.05^{\circ}$ was applied to record the XRD patterns in the $2 \theta$ range of degree of $20-60^{\circ}$ is shown in Fig. 7. The XRD results show that $\mathrm{Cu}_{2} \mathrm{O}$ is the only oxidation products with a small amount of $\mathrm{Cu}$ after the oxidation at 400 and $500{ }^{\circ} \mathrm{C}$. XRD peak at $2 \theta=36.54^{\circ}$ and $2 \theta=29.60^{\circ}$ corresponding to (111) and (110) plane of cubic $\mathrm{Cu}_{2} \mathrm{O}$ structure, in addition (200) plane is the most prominent peak at $2 \theta=42.6^{\circ}$ in the sample. The weak two peaks at $2 \theta=43.8^{\circ}$ and $2 \theta=50.9^{\circ}$ can be readily indexed as (111) and (200) crystal plane of cubic $\mathrm{Cu}$.

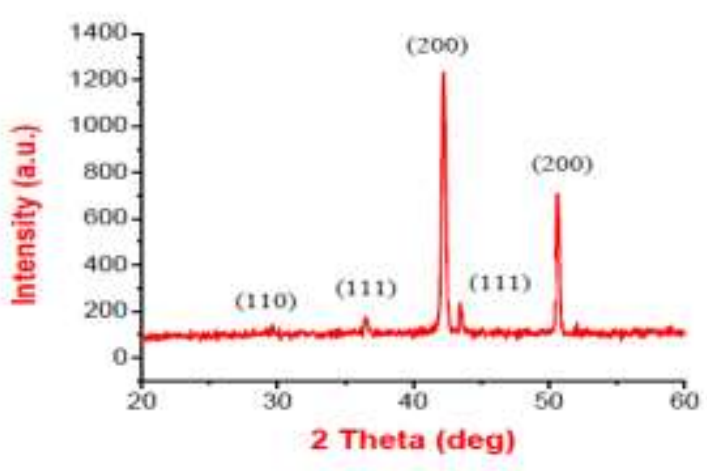

Figure.7 XRD patterns of Sample (S4) 


\section{CONCLUSION}

$\mathrm{Cu}_{2} \mathrm{O}$ nanowires have been successfully grown by heating copper foil in the presence of oxygen rich environment using a hot tube vacuum thermal evaporation under the optimal setting parameters and oxygen flow rate of 0.12 psi. These resulted in $\mathrm{Cu}_{2} \mathrm{O}$ nanowires with improved densities, sizes and most important was higher aspect ratio. The EDX spectrum shows strong $\mathrm{Cu}_{2} \mathrm{O}$ signals from the fabricated nanostructures and XRD will provide information on the crystallinity of $\mathrm{Cu}_{2} \mathrm{O}$ nanowires that produced by oxidation method.

\section{ACKNOWLEDGEMENTS}

This work was supported in part by the Malaysian Minstry of Higher Education (MOHE) through the Research Management Centre (RMC), Universiti Technology Malaysia through the Research Grant (Vot No. Q.J130000.2509.06H69). This support is gratefully acknowledged. The authors would also like to thank everyone involved in making the project a success.

\section{REFERENCES}

[1] J. Ghijsen, L.H. Tjeng, J. van Elp, H. Eskes,

J. Westerink,G.A. Sawatzky, M.T. Czyzyk, Phys. Rev. B 38 (1988) 11322.

[2] L. C. Olsen, R. C. Bohara, and M.W.Urie, Applied Physics Letters, 34 (1) (1979), 47-49.

[3] K. Han, M. Tao, Sol. Energy Mater. Sol. Cells 93 (2009) 153.

[4] C.A.N. Fernando, S.K. Wetthasinghe, Sol. Energy Mater. Sol. Cells 63 (2000) 299.

[5] G Filipi c c and U Cvelbar, Nanotechnology 23 (2012) 194001.

[6] A. Paracchino, J. Cornelius Brauer, J.-E. Moser, E. Thimsen, and M. Graetzel, The Journal of Physical Chemistry C, 116 (13) (2012) 7341-7350.

[7] Y.S. Kim et al.,Sensor Actuat. B-Chem., 135 (2008) 298.

[8] T. J. Hsueh, C. L. Hsu, S. J. Chang, P. W. Guo, J. H. Hsieh, and I.C. Chen, Scripta Materialia, 57 (1) (2007) 53-56.

[9] K. P. Musselman, A. Marin, L. Schmidt-Mende, and J. L.MacManus-Driscoll, Advanced Functional Materials, 22 (10) (2012) 2202-220
[10] Jianbo Liang, Naoki Kishi, Tetsuo Soga, and Takashi, Journal of Nanomaterials, (2011) 268508.

[11] F. Lanza, R. Feduzi, and J. Fuger, Journal of Materials Research, 5 (8) (1990) 1739- 1744.

[12] D. Chen, G. Shen, K. Tang, and Y. Qian, Journal of Crystal Growth, 254 (1-2) (2003) 225-228.

[13] C. T. Hsieh, J. M. Chen, H. H. Lin, and H. C. Shih, Applied Physics Letter, 82 (19) (2003) 3316-3318.

[14] J. Liang, N. Kishi, T. Soga, and T. Jimbo, Applied Surface Science, 257 (1) (2010) 62-66.

[15] K. Zhang, C. Rossi, C. Tenailleau, P. Alphonse, and J.-Y. Chane-Ching, Nanotechnology, 18 (27) (2007) 275607.

[16] R. C. Wang and C. H. Li, Crystal Growth and Design, 9 (5) (2009) 2229-2234.

[17] K. Zhang, Y. Yang, E. Y.B. Pun, and R.Shen Nanotechnology, 21 (23) (2010) 7.

[18] J. Chen, B. J. Hansen, and G. Lu, Journal of Nanomaterials, 1 (2008) 830474

[19] A. M.B. Gon, alves, L. C. Campos, A. S. Ferlauto, and R. G.Lacerda, Journal of Applied Physics, 106 (3) (2009) 34303.

[20] X. Jiang, T. Herricks, and Y. Xia, Nano -Letters, 2 (12) (2002) 1333-1338.

[21] C. H. Xu, C. H. Woo, and S. Q. Shi, Superlattices and Microstructures, 36 (1-3) (2004) 31-38.

[22] C. Rossi, K. Zhang, D. Esteve, Journal of Microelectromechanical Systems, 16 (4) (2007) 919-931.

[23] A. M. B. Gon, alves, L. C. Campos, A. S. Ferlauto, and R.G. Lacerda, Journal of Applied Physics, 106 (3) (2009) 034303.

[24] Fa-chun Laia; Suan-zhi Lina; Zhi-gao Chena; Hai-long Hub; Li-mei Lina, Chin. J. Chem. Phys, 26 (5) (2013) 585-589

[25] Seung Ki Baek, Ki Ryong Lee, and Hyung Koun Cho, Journal of Nanomaterials, (2013) 421371.

[26] JianBo Liang, Naoki Kishi, Tetsuo Soga, Takashi Jimbo, Mohsin Ahmed, Thin Solid Films, 520 (2012) 2679-2682.

[27] J.T. Chena, F. Zhang a, J. Wanga, G.A Zhang a, B.B. Miaoa, X.Y. Fan a, D. Yana, P.X. Yan a,b, Journal of Alloys and Compounds, 454 (2008) 268-273.

[28] Rediola Memaa, Lu Yuan a, Qingtian Dub, Yiqian Wangb, Guangwen Zhou, Chemical Physics Letters 512 (2011) 87-91. 